\title{
Perancangan Aplikasi Penentu Jurusan IPA atau IPS Pada SMA Menggunakan Fuzzy Logic
}

\author{
Yusuf Kurnia ${ }^{1}$ Dharma Sagara ${ }^{2}$ \\ ${ }^{1}$ Universitas Buddhi Dharma, Teknik Informatika, Banten, Indonesia
}

\section{JEJAK PENGIRIMAN}

Diterima: Agustus 15, 2017

Revisi Akhir: Agustus 20, 2017

Tersedia Online: September 13, 2017

\section{KATA KUNCI}

Logika Fuzzy, Metode Tsukamoto, Penjurusan SMA

KORESPONDENSI

Telepon: 08983591589

E-mail: yusufkurnia.iuz@gmail.com

\begin{abstract}
A B S T R A K
Penelitian ini didasari oleh kurangnya persiapan siswa dalam memilih penjurusan yang tepat akan berdampak pada pelajaran yang nantinya akan di pelajarinya. Perkembangan teknologi yang semakin canggih yang sekarang telah membuat banyak organisasi atau lembaga menggunakannya sebagai media yang pengolahan data, mendukung kemampuan Komputer dalam pengolahan data telah sangat mendukung dalam menghadirkan information bahwa mudah, akurat dan berkualitas. Seperti dengan organisasi atau lembaga lain. Pada penelitian akan menerapkan logika fuzzy metode Tsukamoto dalam mencari penjurusan yang tepat pada siswa di SMA. Keuntungan penggunaan logika fuzzy adalah dapat melakukan observasi objektif terhadap nilainilai yang bersifat subjektif. Adapun variable yang akan diproses dalam logika fuzzy adalah nilai dan minat. Hasil tes siswa akan menjadi nilai masukkan yang kemudian diproses didalam logika fuzzy. Nilai tersebut diproses kedalam tiga tahapan logika fuzzy yaitu fuzzifikasi, penalaran dan defuzzifikasi. Hasil dari penjurusan ini yang kemudian akan menjadi panduan siswa dalam mengoptimasi proses pembelajaran.
\end{abstract}

\section{PENGANTAR}

Pemilihan jurusan bagi siswa SMA/Ma sederajat merupakan awal dari pemilihan karir ke depannya. Penjurusan diperkenalkan sebagai upaya untuk lebih mengarahkan siswa berdasarkan minat dan kemampuan akademiknya. Siswa-siswa yang mempunyai kemampuan sains dan ilmu eksakta yang baik, biasanya akan memilih jurusan IPA, dan yang memiliki minat pada sosial dan ekonomi akan memilih jurusan IPS. Namun faktor utama yang menentukan penjurusan adalah nilai akademik siswa, minat siswa, kapasitas kelas IPA dan nilai tes IQ. Nilai tes IQ adalah salah satu alat ukur kecerdasan seseorang.

\section{METODE}

Fuzzy inference system (FIS) adalah suatu kerangka komputasi yang didasarkan pada teori himpunan fuzzy, aturan fuzzy dan penalaran fuzzy. Secara garis besar, input crisp dimasukkan ke FIS. Fuzzy inference system (FIS) dapat dilakukan dengan tiga metode, yaitu dengan metode Mamdani, metode Sugeno dan metode Tsukamoto Metode yang dipilih untuk menyelesaikan bidang studi adalah metode Tsukamoto dengan bahasa pemrograman PHP. Logika Fuzzy merupakan salah satu cabang dari bidang soft-computing. [1], menjelaskan bahwa logika fuzzy pertama kali 
diperkenalkan pada tahun 1965 oleh seorang professor ilmu computer di Universitas of California di Barkley yang bernama Lothfi A. Zadeh. Logika fuzzy merupakan suatu teori himpunan logika yang dikembangkan untuk mengatasi konsep nilai yang terdapat diantara kebenaran (true) dan kesalahan (false). Zadeh mengemukakan bahwa setiap persoalan yang ada dapat diselesaikan tanpa menggunakan logika fuzzy, tetapi apabila menggunakan logika fuzzy akan mempercepat dan mempermudah penyelesaian terhadap suatu masalah. [2], menjelaskan pada himpunan tegas (crisp), nilai keanggotaan suatu item $\mathrm{x}$ dalam suatu himpunan A, yang sering ditulis dengan $\mu \mathrm{A}[\mathrm{x}]$, memiliki 2 kemungkinan, yaitu: satu (1), yang berarti bahwa suatu item menjadi anggota dalam suatu himpunan, atau nol (0), yang berarti suatu item tidak menjadi anggota dalam suatu himpunan. [3], mengemukan bahwa pada metode Tsukamoto, setiap konsekuen pada aturan yang berbentuk IF-Then harus dipresentasikan dengan suatu himpunan fuzzy dengan fungsi keanggotaan yang monoton. Sebagai hasilnya, output hasil inferensi dari tiap-tiap aturan diberikan secara tegas (crisp) berdasarkan $\alpha$-predikat (fire strength). Hasil akhirnya diperoleh dengan menggunakan rata-rata terbobot.

[4],'Interaksi Manusia dan komputer dimulai dengan mengkombinasikan metode pengumpulan data dan psikologi yang dikembangkan dengan teknologi informasi. Perpaduan tersebut menghasilkan interaksi yang kuat antara user interface dan computer user."

[5]"data adalah deskripsi dasar dari benda, peristiwa, aktivitas dan transaksi yang direkam, dikelompokkan, dan disimpan tetapi belum terorganisir untuk menyampaikan arti tertentu.Berdasarkan teori ahli diatas dapat disimpulkan bahwa, data adalah deskripsi dasar dari benda, peristiwa, aktivitas dan transaksi yang direkam, dikelompokkan, dan disimpan dalam jumlah yang besar tetapi belum diolah."

\section{HASIL}

Proses awal sistem yang dilakukan adalah siswa melakukan test. Hasil tes tersebut akan berupa sebuah bilangan riil. Bilangan riil tersebut yang akan masuk ke dalam proses fuzzy logic. Pada awal tahapan fuzzy logic, bilangan riil tersebut akan dimasukan kedalam tahapan fuzzifikasi. Proses fuzzifikasi mengubah bilangan riil tersebut menjadi bilangan fuzzy sehingga dapat diproses pada tahapan berikutnya. Proses berikutnya adalah proses penalaran metode Tsukamoto. Dengan bantuan aturan fuzzy, bilangan fuzzy yang telah dihasilkan diinterpretasikan kedalam setiap aturan fuzzy sehingga menghasilkan keluaran fuzzy baru. Hasil keluaran fuzzy ini kemudian diproses kedalam tahapan defuzzifikasi. Setelah proses defuzzifikasi maka didapatkan bilangan riil baru yang digunakan untuk menentukan penjurusan yang sesuai. Adapun flowchart algoritma sistem usulan dapat dilihat sebagai berikut: 


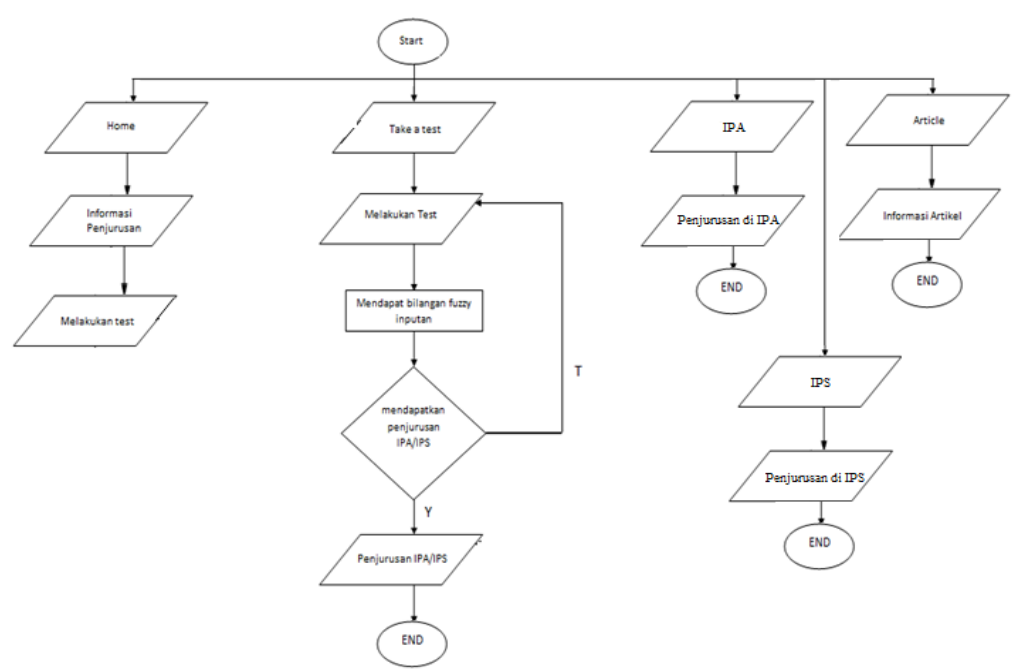

Gambar 1: Flowchart Algoritma Aplikasi Usulan

Table 1. Tabel Pakar

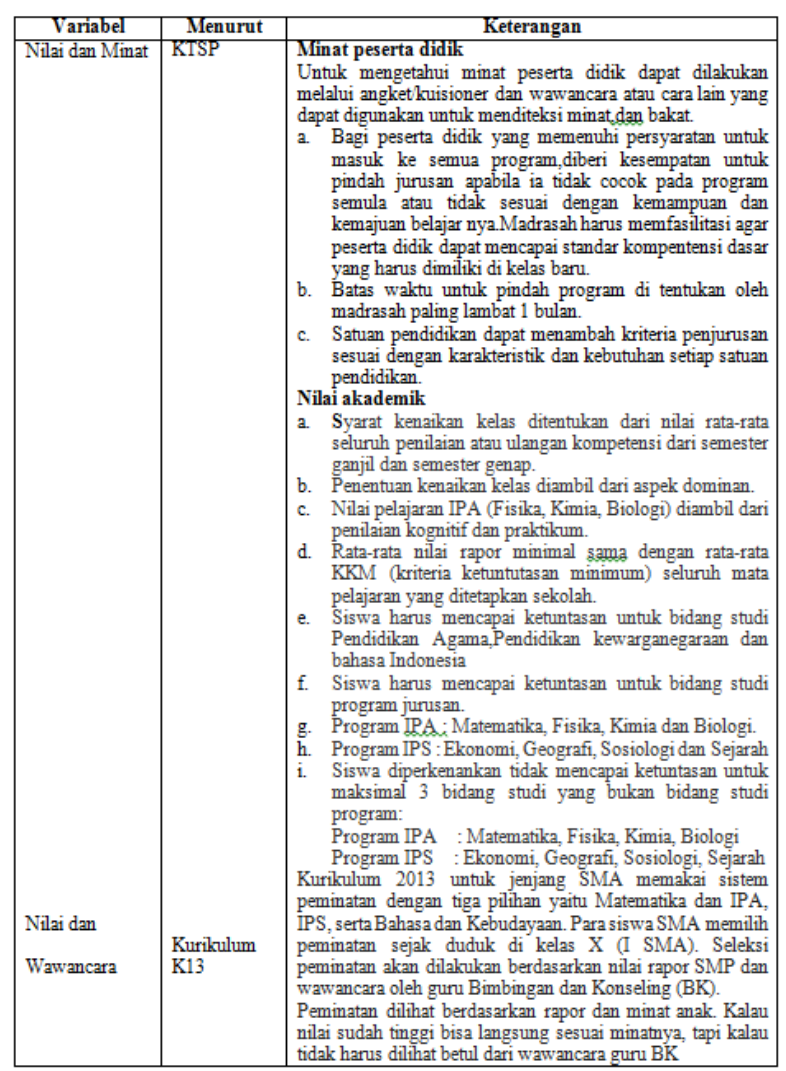

Pada sistem ini, terdapat 2 buah himpunan yang akan digunakan dalam menentukan penjurusan yaitu IPA dan IPS. Setiap penjurusan masing-masing memiliki 2 variabel. Adapun variabel masukan tiap penjurusan adalah: NIPA dan MINAT pada himpunan IPA dan NIPS dan MINAT pada himpunan IPS. Variabel-variabel ini terdiri dari tiga himpunan fuzzy yaitu rendah, sedang dan tinggi yang ditunjukkan pada gambar 2 dan 3. Fungsi keanggotaan pada setiap himpunan dirumuskan sebagai berikut:

$$
\begin{aligned}
& \mu \operatorname{RENDAH}(x)= \begin{cases}1 & ;(x \leq 55) \\
\frac{70-x}{15} & ;(55<x<70)\end{cases} \\
& 0 \quad ;(x \geq 70) \\
& \mu \text { sedang }(x)=\frac{\{x-55}{15} ;(55<x<70) \\
& \frac{85-x}{15} ;(70<x<85) \\
& 0 \quad ;(x \geq 85) \&(\mathrm{x} \leq 55) \\
& \mu \text { tinggi }(x)=\{1 \quad ;(x \geq 85) \\
& \frac{x-70}{15} ;(70<x<85) \\
& 0 \quad ;(x \leq 70)
\end{aligned}
$$

Fungsi keanggotaan pada setiap himpunan dirumuskan sebagai berikut:

$$
\begin{aligned}
& \mu \operatorname{RENDAH}(x)=\{1 \quad ;(x \leq 30) \\
& \frac{50-x}{20} ;(30<x<50) \\
& 0 \quad ;(x \geq 50)
\end{aligned}
$$




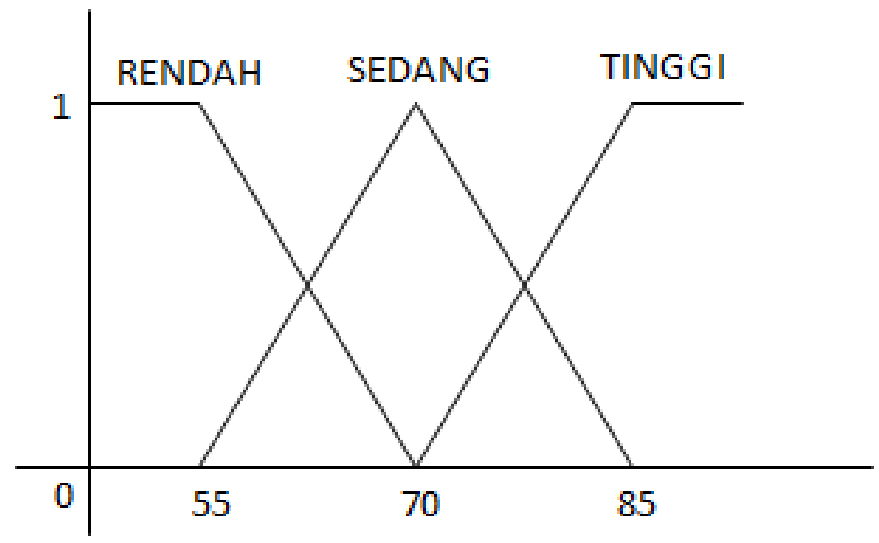

Gambar 2: Himpunan Fuzzy Variabel Inputan Nilai

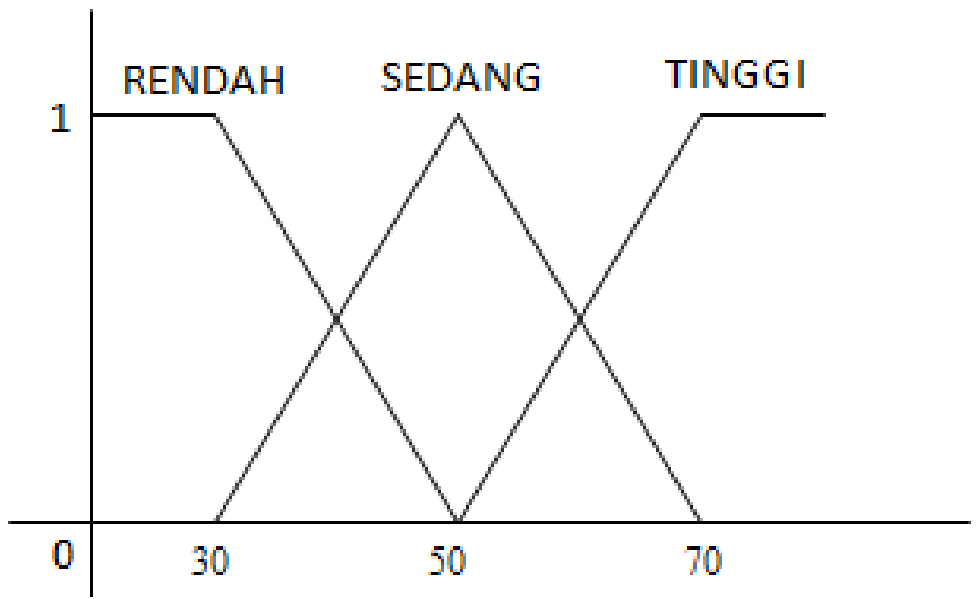

Gambar 3: Himpunan Fuzzy Variabel Inputan Minat

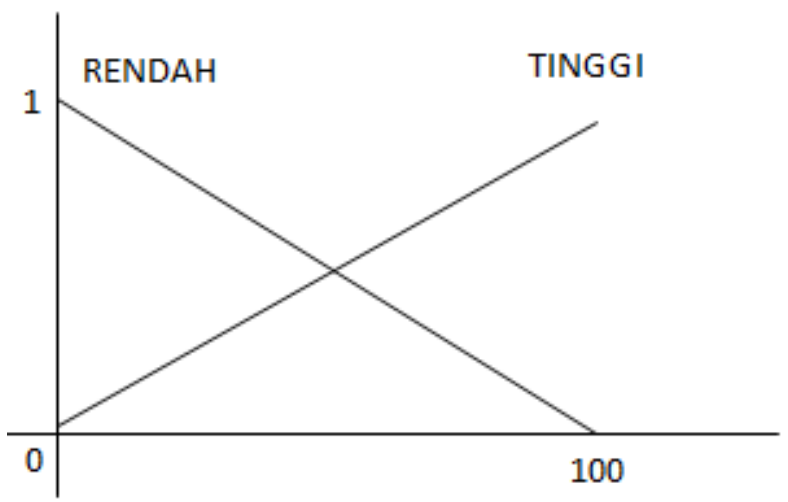

Gambar 4: Himpunan Fuzzy Variabel Keluaran 


$$
\begin{aligned}
& \mu \operatorname{RENDAH}(x)=\{1 \quad ;(x \leq 30) \\
& \frac{50-x}{20} ;(30<x<50) \\
& 0 ;(x \geq 50) \\
& \mu \text { sedang }(x)=\frac{\{x-30}{20} ;(30<x<50) \\
& \begin{array}{ll}
\frac{70-x}{20} & ;(50<x<70) \\
0 & ;(x \geq 70) \&(\mathrm{x} \leq 30)
\end{array} \\
& \mu \text { tinggi }(x)=\{1 \quad ;(x \geq 70) \\
& \frac{x-50}{20} ;(50<x<70) \\
& 0^{20} ;(x \leq 50)
\end{aligned}
$$

Variabel output pada penelitian ini berupa perankingan yang merupakaan dasar dari pemilihan personalitas. Variabel output ini terdiri dari dua himpunan fuzzy, yaitu rendah dan tinggi seperti yang ditunjukan pada gambar 4. Fungsi keanggotaan pada setiap himpunan dirumuskan sebagai berikut:

$$
\begin{aligned}
& \mu \operatorname{RENDAH}(x)=\{1 \quad ;(x \leq 0) \\
& \frac{100-x}{100} ;(0<x<100) \\
& 0 \quad ;(x \geq 100) \\
& \mu \text { tinggi }(x)=\{1 \quad ;(x \geq 100) \\
& \frac{x-0}{100} ;(0<x<100) \\
& 0 ;(x \leq 0)
\end{aligned}
$$

Adapun aturan fuzzy setiap himpunan adalah sebagai berikut:

Himpunan IPA

[r1] IF NIPA tinggi and MINAT tinggi then

IPA tinggi

[r2] IF NIPA tinggi and MINAT sedang then

IPA tinggi

[r3] IF NIPA tinggi and MINAT rendah then

IPA rendah

[r4] IF NIPA sedang and MINAT tinggi then

IPA tinggi

[r5] IF NIPA sedang and MINAT sedang then IPA tinggi

[r6] IF NIPA sedang and MINAT rendah then IPA rendah

[r7] IF NIPA rendah and MINAT tinggi then

IPA rendah

[r8] IF NIPA rendah and MINAT sedang then IPA rendah

[r9] IF NIPA rendah and MINAT rendah then IPA rendah

Himpunan IPS

[r1] IF NIPS tinggi and MINAT tinggi then IPS tinggi

[r2] IF NIPS tinggi and MINAT sedang then IPS tinggi [r3] IF NIPS tinggi and MINAT rendah then

IPS rendah

[r4] IF NIPS sedang and MINAT tinggi then

IPS tinggi

[r5] IF NIPS sedang and MINAT sedang then IPS tinggi

[r6] IF NIPS sedang and MINAT rendah then IPS rendah

[r7] IF NIPS rendah and MINAT tinggi then IPS rendah

[r8] IF NIPS rendah and MINAT sedang then IPS rendah

[r9] IF NIPS rendah and MINAT rendah then IPS rendah.

\section{PEMBAHASAN}

Penentuan keputusan diawali dengan proses perhitungan derajat keanggotaan variable input di setiap himpunan yang ada pada setiap aturan. Kemudian, susunan antar aturan dilakukan untuk mencari nilai $\alpha$ -

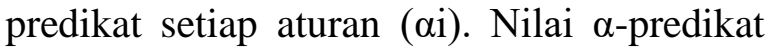
sangat tergantung pada operator yang digunakan. Pada operator and, nilai $\alpha$ predikat diberikan " $\mathrm{x} 1$ is a1 and $\mathrm{x} 2$ is a2" dirumuskan pada pada persamaan berikut:

$\alpha i=\mu A 1 \cap A 2=\min (\mu A 1(x 1), \mu A 2(x 2))$

Untuk mendapatkan nilai output (crisp) adalah dengan mengubah input menjadi suatu bilangan pada domain himpunan fuzzy tersebut atau yang dimaksud dengan defuzIFikasi. Setelah diperoleh nilai $\alpha$ i, maka selanjutnya akan dilakukan proses perhitungan nilai setiap konsekuen setiap aturan (zi) sesuai dengan fungsi keanggotaan yang digunakan.

Metode defuzIFikasi dalam metode tsukamoto adalah defuzIFikasi rata-rata terpusat (center average defuzzyfier) yang dirumuskan pada persamaan berikut:

$Z=\sigma \propto i z i n i=1 \sigma \propto i z i n i=1 \sigma \propto i n i=1$

Dimana pada persamaan di atas z merupakan hasil defuzzIFikasi, sedangkan $\alpha i$ adalah nilai keanggotaan antiseden, dan zi adalah hasil inferensi tiap aturan.

Setelah proses logika fuzzy, telah didapatkan hasil dari masing-masing himpunan personalitas (IPA, IPS). Hasil himpunan akan berupa angka 0-100. Kemudian angka 
tersebut akan menjadi suatu kondisi didalam himpunan yaitu sebagai berikut:

IF IPA $>=$ IPS then IPA

IF IPA $<=$ IPS then IPS

Contoh uji kasus yang akan digunakan adalah himpunan IPA saja.

1. Fuzzifikasi

Dalam himpunan IPA terdapat 2 variabel yaitu NIPA dan MINAT. Sebagai contoh nilai NIPA adalah 80 dan nilai MINAT adalah 70 .
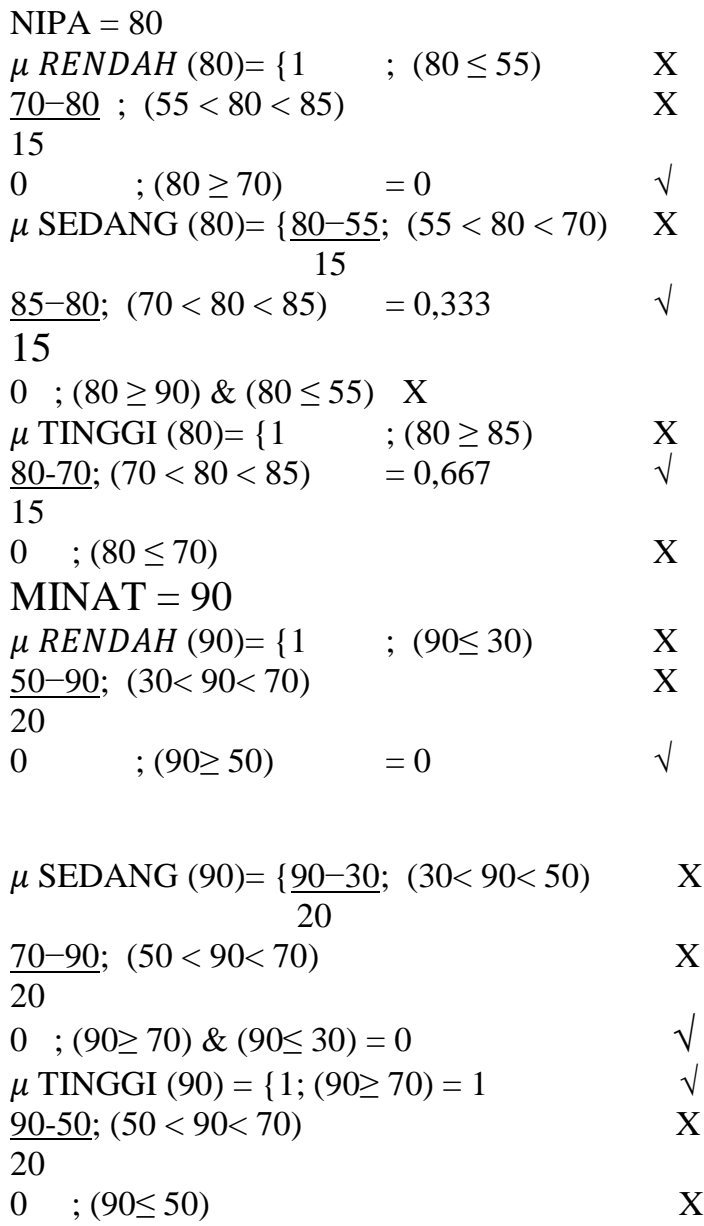

Tahap ini merupakan susunan antar aturan yang dilakukan untuk mencari nilai $\alpha$ predikat setiap aturan ( $\alpha i)$. Nilai dari himpunan fuzzy dari masing-masing variabel kemudian akan dimasukkan kedalam 9 aturan fuzzy himpunan IPA guna mendapatkan nilai $\alpha$-predikat tiap aturan. Operator yang digunakan untuk menghubungkan aturan-aturan input adalah operator AND yang menggambarkan antara input-output adalah IF - THEN.

[R1] IF NIPA tinggi AND MINAT tinggi THEN IPA TINGGI $\alpha$-predikat $1=\min (\mu$ NIPA TINGGI $(80) \cap \mu$ MINAT TINGGI (90))

$$
\begin{aligned}
& =\min (0,667 \cap 1) \\
& =0,667
\end{aligned}
$$

Setelah nilai $\alpha$-predikat 1 diketahui maka dicari nilai $(\mathrm{z})$ didalam himpunan hasil yaitu NIPA TINGGI.

$\begin{array}{ll}\mu \text { TINGGI (z1) } & =\frac{\mathrm{z}-0}{100} \\ 0,667 & =\frac{\mathrm{z}-0}{100} \\ \mathrm{z} 1 & =66,7\end{array}$

Tahap ini disebut juga tahap penegasan input dan proses. Penegasan ini adalah suatu himpunan fuzzy yang diperoleh dari komposisi aturan-aturan fuzzy, sedangkan output yang dihasilkan merupakan suatu bilangan pada domain himpunan fuzzy tersebut. Hasil aturan seperti data diatas adalah:

$$
\begin{aligned}
\mathrm{Z} \quad & =\frac{\alpha 1 \mathrm{z} 1+\alpha 2 \mathrm{z} 2+\alpha 3 \mathrm{z} 3+\alpha 4 \mathrm{z} 4+\ldots+\alpha 9 \mathrm{z} 9}{\alpha 1+\alpha 2+\alpha 3+\alpha 4+\ldots+\alpha 9} \\
& =\{(0,667 \times 66,7)+0+0+(0,337 * 33,7)+0 \\
& +0+0+0+0 /\{0,667+0+0+0,333+0+ \\
& 0+0+0+0\} \\
& =\frac{55,846}{1,004} \\
& =55,623=>56
\end{aligned}
$$

Maka nilai IPA yang didapatkan adalah 56.

\section{KESIMPULAN}

Setelah menyelesaikan perhitungan dengan mnggunakan algoritma Fuzzy Logic metode Tsukamoto dan menerapkan hasil pada aplikasi berbasis web, maka dapat diambil kesimpulan sebagai berikut:

1. Algoritma Fuzzy Logic dengan menggunakan metode Tsukamoto sangat membantu dalam pembentukan pola untuk menentukan minat penjurusan siswa SMA.

2. Dengan adanya penelitian ini dapat membantu mempersiapkan diri siswa dalam menentukan jurusan.

3. Dengan adanya penelitian ini membantu siswa dalam memfokuskan proses pembelajaran. 


\section{REFERENSI}

Irwansyah, Edy \& Faisal, Muhammad, Advanced Clustering: Teori dan aplikasi. Deepublish, Yogyakarta, 2015.

Sri Kusuma Dewi, Aplikasi Logika Fuzzy Untuk Sistem Pendukung Keputusan. Andi Offset, Yogyakarta, 2010.

Thamrin, Fanoeel Sediyono E, Studi Interferensi Fuzzy Tsukamoto Untuk Penentuan Faktor Pembeban Trafo PLN. Teknologi Informasi, Semarang, 2012.

Shneiderman, Ben \& Plaisant, Catherine, Designing the User Interface: Strategic for Effective Human-computer Interaction. Addison-Wesley, Amerika Serikat, 2010.

Turban, Efraim \& Rainer, R. Kelly, Introduction to Information Systems : Supporting and Transforming Business. Wiley, Hoboken, Amerika Serikat, 2008.

\section{RIWAYAT HIDUP}

Yusuf Kurnia Lulus pada Program Studi Sistem Informasi (S1) di bidang Perusahaan, 2009, Program Studi Ilmu Komputer (S2) di bidang Teknologi Sistem Informasi. Saat ini Sebagai Dosen Tetap pada Program Studi Teknik Informatika, Universitas Buddhi Dharma.

Dharma Sagara Lulus pada Program Studi Teknik Informatika (S1) di bidang Jaringan, 2017. 